\title{
Incidence of neurological complications of surgery for congenital heart disease
}

\author{
P Fallon, J M Aparício, M J Elliott, F J Kirkham
}

\begin{abstract}
A total of 523 cardiac surgical discharge summaries were searched for recorded evidence of adverse neurological events occurring between operation and time of discharge. Neurological events were recorded in 31 and included one or more of seizure disorder $(n=16)$, pyramidal signs $(n=11)$, extrapyramidal signs $(n=8)$, coma $(n=6)$, and neuro-ophthalmic deficits $(n=6)$.

There were significantly more adverse neurological events after repairs for arch anomalies (16.6\% of cases). There was also an association with the length of cardiopulmonary bypass and a period of low perfusion pressure either intraoperatively or postoperatively.

Of the 19 out of 23 survivors in whom long term outcome data were available, four were normal and six had persisting neurological problems directly related to the perioperative period. In a further nine of the 19 survivors, established preoperative neurodevelopmental abnormality probably contributed to their present neurological status, in addition to perioperative events.

In view of the way these data were collected, this study must represent the minimum incidence of neurological events in children undergoing cardiac surgery.

(Arch Dis Child 1995; 72: 418-422)
\end{abstract}

Keywords: congenital heart disease, heart surgery, brain.

The mortality associated with the surgical repair of congenital heart defects has fallen dramatically in the last 25 years and is now less than $10 \%$ in most major units. ${ }^{1}$ As mortality has fallen, concern has been raised that an underlying neurological morbidity has been exposed. ${ }^{2}$ The incidence of this neurological morbidity in children is not known, yet this information is essential for the planning of relevant prospective studies into underlying pathophysiology in the population at risk.

Relatively simple cardiac surgery may be carried out using a closed heart approach. For more complex procedures, the heart must be opened and cardiopulmonary bypass used. During bypass, venous blood is drained from the right side of the heart, via a cannula to a pump system. The blood is then oxygenated, cooled, and pumped back to the left side of the heart via an aortic cannula. For most bypass procedures, the aorta is also clamped proximal to this cannula. In some complex surgical procedures, complete circulatory arrest may be required for a period of time. For this the patient is profoundly cooled $\left(<20^{\circ} \mathrm{C}\right)$ and the pump is stopped altogether. ${ }^{3}$

Previous studies in both adults and children have investigated the effect of these various bypass techniques on cerebral haemodynamics and some have looked at the relationship with subsequent neurological outcome. ${ }^{45}$ There are, however, very few data that define the overall morbidity or relate it to any particular diagnosis or surgical procedure.

The present study is a retrospective review of a consecutive series of patients undergoing cardiac surgery, at the Hospital for Sick Children, Great Ormond Street. The purpose of the study was to establish the frequency of immediate neurological events after cardiac surgery in this unit and to examine some of the factors associated with this morbidity.

\section{Methods}

Five hundred and twenty three surgical discharge summaries, created during a one year period, November 1990-October 1991, were searched for evidence of adverse neurological events occurring between operation and time of discharge. By consulting the register of admissions, we determined that this accounted for $96 \%$ of all patients undergoing cardiac surgery at the Hospital for Sick Children during the one year time period chosen. The summaries are written around the time of discharge by the cardiac surgical senior registrar by extraction from the patient's notes. The information obtained was supplemented by the perfusion records, the operation notes, and the hospital records.

Patients were initially grouped by cardiac diagnosis based on the International Classification of Diseases, ninth revision (ICD9), since the UK government currently requires returns of data in this form. We then regrouped them in order to reflect the underlying pathology more closely. Complex diagnoses were reviewed by an independent consultant paediatric cardiologist. The final cardiac diagnostic groups were defined as follows:

- Transposition of the great arteries (TGA) (all sorts of transposition, simple TGA, 'corrected' TGA, TGA and ventricular septal defect, double outlet right ventricle); - Right ventricular outflow tract obstruction (tetralogy of Fallot or nearly Fallot's Dr P Fallon, Neurosciences Unit, The Wolfson Centre, Mecklenburgh Square, London WCIN 2AP.

Accepted 2 February 1995 
for example, double outlet right ventricle, subaortic ventricular septal defect, and pulmonary valve stenosis or atresia);

- Left to right shunts (ventricular septal defect, atrial septal defect, atrioventricular septal defect, patent ductus arteriosus);

- Coarctation of the aorta (all arch anomalies including interrupted aortic arch)*;

- Left sided valve lesions (aortic valve disease, mitral valve disease);

- Complex conditions (including truncus arteriosus, univentricular heart, and complex combinations of the above).

Any insult to the central or peripheral nervous system, was recorded as an adverse neurological event. Neurological events were grouped as follows:

- Pyramidal signs (hemiparesis, quadriparesis);

- Extrapyramidal signs (dystonia, chorea);

- Coma (including fluctuating levels of consciousness);

- Neuro-ophthalmic defects (gaze palsies, visual field defects);

- Miscellaneous disorders including Horner's syndrome secondary to brachial plexus injury, vocal cord palsy, isolated bulbar palsy, and transient ischaemic episode. Important variables of the surgery or postoperative period were noted, for example:

- Length of cardiopulmonary bypass;

- Periods of low perfusion pressure;

- Prolonged ventilation on the intensive care unit ( $>48$ hours).

Intraoperatively, if the perfusion charts contained at least two consecutive entries of mean arterial pressure (MAP) below $40 \mathrm{~mm} \mathrm{Hg}$ a record was made, although the frequency of recording of entries onto the perfusion charts was not known. Forty $\mathrm{mm} \mathrm{Hg}$ was chosen arbitrarily as a cut off point for perfusion pressure. This value was chosen because in a previous study, carried out by this group, loss of cerebrovascular reactivity to carbon dioxide was found during cardiopulmonary bypass in children when the MAP fell below this level, suggesting that compensatory vasodilatation may not occur below this point. ${ }^{6}$ Further studies of non-traumatic coma in children have shown poor outcome when mean cerebral perfusion pressure (CPP) fell below $40 \mathrm{~mm}$ $\mathrm{Hg}$, irrespective of age (CPP $=$ MAPintracranial pressure). ${ }^{78}$

Postoperatively, a record was made if the notes had emphasised that there had been difficulty maintaining the child's perfusion pressure despite inotropic support. The numerical value was not known for these cases.

Table 1 Outcome of patients undergoing cardiac surgery by diagnosis

\begin{tabular}{|c|c|c|c|c|c|}
\hline Diagnostic group & $\begin{array}{l}\text { Total No } \\
\text { of patients }\end{array}$ & $\begin{array}{l}\text { No of } \\
\text { deaths }\end{array}$ & $\begin{array}{l}\text { Deaths } \\
(\%)\end{array}$ & $\begin{array}{l}\text { No of adverse } \\
\text { neurological events }\end{array}$ & $\begin{array}{l}\text { Adverse neurological } \\
\text { events (\%) }\end{array}$ \\
\hline $\begin{array}{l}\text { TGA } \\
\text { Right ventricular outflow }\end{array}$ & 52 & 10 & $19 \cdot 2^{\star}$ & 2 & $3 \cdot 8$ \\
\hline $\begin{array}{l}\text { tract obstruction } \\
\text { Left to right shunts } \\
\text { Arch anomalies } \\
\text { Left sided valve lesions } \\
\text { Complex }\end{array}$ & $\begin{array}{r}134 \\
209 \\
36 \\
25 \\
67\end{array}$ & $\begin{array}{l}7 \\
8 \\
3 \\
2 \\
7\end{array}$ & $\begin{array}{r}5 \cdot 2 \\
3 \cdot 8 \\
8 \cdot 3 \\
8 \cdot 0 \\
10 \cdot 4\end{array}$ & $\begin{array}{r}11 \\
6 \\
6 \\
2 \\
4\end{array}$ & $\begin{array}{l}8 \cdot 2 \\
2 \cdot 9 \\
16 \cdot 6^{\star \star} \\
11 \\
5 \cdot 9\end{array}$ \\
\hline Total & 523 & 37 & $7 \cdot 1$ & 31 & 5.9 \\
\hline
\end{tabular}

${ }^{\star} \mathrm{p}<0.05 ;{ }^{\star \star} \mathrm{p}<0.01$.
The families and general practitioners of those patients known to be alive were surveyed in order to establish the long term effect of any neurological event. Where possible, further information was obtained from copies of neurological and developmental examinations carried out by local paediatricians or paediatric neurologists.

\section{STATISTICS}

Differences between proportions were assessed for a priori significance by constructing $2 \times k$ tables and using the $\chi^{2}$ statistic; if significant, differences between groups were then assessed by constructing $2 \times 2$ tables with the $\chi^{2}$ statistic and Fisher's exact test as appropriate. Patients were grouped according to immediate outcome and differences in perioperative factors were determined by analysis of variance and a posterior significance testing using a modified $t$ test (adjusting $\mathrm{p}$ values by the Bonferoni method).

\section{Results}

There was no significant difference in mean age between those children who were subsequently normal and those who had some form of adverse neurological event ( 35 months $v 30$ months; not significant). However, the mean age of patients who subsequently died was significantly younger ( 35 months $v 12$ months; $\mathrm{p}<0.05$ ).

Death rates and adverse neurological events for children with different cardiac pathologies were compared (table 1). Only those patients with the various forms of transposition of the great arteries had a significantly higher incidence of death $(p<0 \cdot 05) . \star \star 16.6 \%$ of patients within the broad classification of arch anomalies were found to have had a neurological event that was significantly greater than in those patients with other cardiac diagnoses $(\mathrm{p}<0.01)$.

Of the 31 patients with adverse neurological events, 16 had seizures, 11 pyramidal signs, eight extrapyramidal signs, six neuroophthalmic deficits, six were unconscious, and there were a further four miscellaneous events. Seizures were therefore apparent in more than $50 \%$ of cases and pyramidal signs in more than a third. Twenty patients had abnormal electroencephalograms (EEGs) out of a total of 24 patients who had EEGs performed.

Of the 523 operations, 411 involved cardiopulmonary bypass, 97 used a closed heart approach, and in 15 patients (14 normal, one died) the records were not available. There was no difference in the proportion with events who had undergone open heart surgery using cardiopulmonary bypass or a closed heart approach $(6 \cdot 1 \%$ and $6 \cdot 2 \%$ respectively). Patients with adverse neurological events had a significantly longer mean cardiopulmonary

«Note: In our view the ICD9 term 'coarctation of aorta' is misleading, since it implies uniformity of diagnosis. Henceforth, this group will therefore be referred to as arch anomalies.

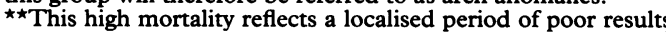
before changing surgical technique for simple transposition. 
bypass time than normal survivors $(113 v 93$ minutes; $p<0.05$ ), as did patients who subsequently died (199 $v 93$ minutes; $\mathrm{p}<0.001)$. There was no significant difference in mean aortic cross clamp time between normal survivors and those with adverse neurological events (48 $v 54$ minutes; not significant). However, the aortic cross clamp time in patients who subsequently died was significantly longer $\left(\begin{array}{lllll}48 & v & 79 & \text { minutes; }\end{array}\right.$

Table 2 Adverse neurological events, investigations and long term outcome

\begin{tabular}{|c|c|c|c|c|c|c|c|}
\hline $\begin{array}{l}\text { Diagnostic group } \\
\text { (cardiac diagnosis) }\end{array}$ & $\begin{array}{l}\text { Patient } \\
\text { No }\end{array}$ & Age & Previous history & $\begin{array}{l}\text { Cardiac operation } \\
\text { (previous operations) }\end{array}$ & $\begin{array}{l}\text { Adverse neurological } \\
\text { events and investigations }\end{array}$ & Long term outcome & $\begin{array}{l}\text { Months } \\
\text { after } \\
\text { surgery }\end{array}$ \\
\hline $\begin{array}{l}\text { RVOTO (pulmonary } \\
\text { atresia, VSD) }\end{array}$ & 5 & $66 \mathrm{~m}$ & Normal & $\begin{array}{l}\text { Total correction of } \\
\text { pulmonary atresia } \\
\text { closure VSD (bilateral } \\
\text { MBTS) }\end{array}$ & $\begin{array}{l}\text { Encephalopathy, mild chorea, } \\
\text { bulbar signs }\end{array}$ & $\begin{array}{l}\text { Poor coordination, } \\
\text { chorea, speech regres- } \\
\text { sion, obsessive } \\
\text { behaviour, short } \\
\text { attention span } \\
\text { General improvement } \\
\text { but still with chorea, } \\
\text { short attention span, } \\
\text { immature behaviour }\end{array}$ & 21 \\
\hline RVOTO (TOF) & 8 & $58 \mathrm{~m}$ & Down's syndrome & Left MBTS & $\begin{array}{l}\text { Right hemiparesis; atrial clot on } \\
\text { echocardiography }\end{array}$ & $\begin{array}{l}\text { Global development } \\
\text { delay }\end{array}$ & 30 \\
\hline RVOTO (TOF) & 10 & $22 \mathrm{~m}$ & Normal & $\begin{array}{l}\text { Emergency repair of TOF } \\
\text { (right MBTS) }\end{array}$ & $\begin{array}{l}\text { Right homonymous hemianopia, } \\
\text { left convergent squint }\end{array}$ & $\begin{array}{l}\text { Left convergent squint, } \\
\text { partially sighted }\end{array}$ & 24 \\
\hline $\begin{array}{l}\text { RVOTO (pulmonary } \\
\text { atresia, IVS) }\end{array}$ & 18 & $1 \mathrm{~d}$ & Normal & Right MBTS & $\begin{array}{l}\text { Generalised seizures, pyramidal } \\
\text { signs, poor vision; EEG: burst } \\
\text { suppression discharges } \\
\text { right >left, computed } \\
\text { tomogram: bilateral parietal } \\
\text { infarcts }\end{array}$ & $\begin{array}{l}\text { Motor delay, poor vision } \\
\text { Mild right hemiparesis, } \\
\text { improved visual } \\
\text { function } \\
\text { 'Functioning at } \\
\text { prelinguistic level' }\end{array}$ & $\begin{array}{r}3 \\
12\end{array}$ \\
\hline RVOTO (TOF) & 20 & $5 \mathrm{~m}$ & Normal & Repair TOF & $\begin{array}{l}\text { Variable tone, involuntary } \\
\text { movements left leg; EEG: slow } \\
\text { activity right >left }\end{array}$ & $\begin{array}{l}\text { Febrile and afebrile } \\
\text { seizures }\end{array}$ & 24 \\
\hline RVOTO (TOF) & 27 & $12 \mathrm{~m}$ & Down's syndrome & Repair TOF & $\begin{array}{l}\text { seizures: generalised, EEG: } \\
\text { spike left anterior hemisphere }\end{array}$ & $\begin{array}{l}\text { Learning difficulties, } \\
\text { language delay }\end{array}$ & 24 \\
\hline $\begin{array}{l}\text { Left-right shunt } \\
\text { (VSD) }\end{array}$ & 12 & $10 \mathrm{~m}$ & $\begin{array}{l}\text { Premature birth } \\
(29 / 40), \\
\text { developmental } \\
\text { delay }\end{array}$ & Patch closure VSD & Dystonic movements & Normal & 24 \\
\hline $\begin{array}{l}\text { Left-right shunt, } \\
\text { (VSD } \times 2 \text {, small } \\
\text { right ventricle) }\end{array}$ & 14 & $26 \mathrm{~m}$ & Normal & Repair VSD (repair VSD) & $\begin{array}{l}\text { Seizures, coma (decerebrate } \\
\text { posture). extrapyramidal signs, } \\
\text { pyramidal signs, right visual } \\
\text { field defect; EEG: excess slow } \\
\text { waves right }>\text { left no discharges, } \\
\text { computed tomogram: cerebral } \\
\text { atrophy, subcortical, } \\
\text { calcification, left subdural }\end{array}$ & $\begin{array}{l}\text { Global developmental } \\
\text { delay; functioning at } \\
24 \text { months (at } 44 \\
\text { months), tremor of } \\
\text { hands, impaired vision } \\
6 / 24 \text { right }=\text { left }\end{array}$ & 18 \\
\hline $\begin{array}{l}\text { Left-right shunt } \\
\text { (VSD) }\end{array}$ & 16 & $43 \mathrm{~m}$ & Down's syndrome & Patch closure VSD & $\begin{array}{l}\text { Abnormal movements, not fixing } \\
\text { or following }\end{array}$ & $\begin{array}{l}\text { Global developmental } \\
\text { delay }\end{array}$ & 24 \\
\hline $\begin{array}{l}\text { Left-right shunt } \\
\text { (AVSD) }\end{array}$ & 24 & $2 \mathrm{~m}$ & Down's syndrome & Two patch repair of AVSD & $\begin{array}{l}\text { Focal seizures left; EEG: severe } \\
\text { bilateral multifocal discharges }\end{array}$ & $\begin{array}{l}\text { Microcephaly, floppy, } \\
\text { global development } \\
\text { delay }\end{array}$ & 18 \\
\hline $\begin{array}{l}\text { Left-right shunt } \\
\text { (VSD) }\end{array}$ & 29 & $5 \mathrm{~m}$ & $\begin{array}{l}\text { DiGeorge syndrome: } \\
\text { previous seizures } \\
\text { associated with } \\
\text { hypocalcaemia, } \\
\text { developmental } \\
\text { delay }\end{array}$ & Closure VSD & $\begin{array}{l}\text { Seizures; EEG: multifocal dis- } \\
\text { charges, computed tomogram: } \\
\text { hypoxic ischaemic changes }\end{array}$ & $\begin{array}{l}\text { Motor disorder, visual } \\
\text { problems, learning } \\
\text { difficulties, language } \\
\text { delay, seizures }\end{array}$ & 18 \\
\hline $\begin{array}{l}\text { Arch anomalies } \\
\text { (recoarctation) }\end{array}$ & 13 & $4 \mathrm{~m}$ & $\begin{array}{l}\text { Premature birth } \\
(27 / 40) \text {, bilateral } \\
\text { ankle clonus, right } \\
\text { porencephaly }\end{array}$ & $\begin{array}{l}\text { Repair recoarctation on } \\
\text { bypass (repair coarcta- } \\
\text { tion) }\end{array}$ & $\begin{array}{l}\text { Focal seizures: right; EEG: } \\
\text { multifocal discharges left }\end{array}$ & $\begin{array}{l}\text { No seizures, left sided } \\
\text { hypertonia, visual } \\
\text { impairment }\end{array}$ & 12 \\
\hline $\begin{array}{l}\text { Arch anomalies } \\
\text { (simple } \\
\text { coarctation) }\end{array}$ & 15 & $21 \mathrm{~m}$ & $\begin{array}{l}\text { Floppy, pyramidal } \\
\text { signs, hearing loss }\end{array}$ & $\begin{array}{l}\text { End to end anastomosis } \\
\text { not on bypass }\end{array}$ & $\begin{array}{l}\text { Seizures: generalised; EEG: } \\
\text { normal }\end{array}$ & $\begin{array}{l}\text { Motor delay, hand } \\
\text { regarding }\end{array}$ & 3 \\
\hline $\begin{array}{l}\text { Arch anomalies } \\
\text { (hypoplastic arch } \\
\text { and aortic } \\
\text { coarctation) }\end{array}$ & 17 & $25 \mathrm{~d}$ & Normal & $\begin{array}{l}\text { Repair hypoplastic arch } \\
\text { and aortic coarctation on } \\
\text { bypass }\end{array}$ & $\begin{array}{l}\text { Seizures, fluctuating level of } \\
\text { consciousness; EEG: } \\
\text { discharges around vertex with } \\
\text { associated tongue and mouth } \\
\text { movements }\end{array}$ & Normal & 12 \\
\hline $\begin{array}{l}\text { Arch anomalies } \\
\text { (simple } \\
\text { coarctation) }\end{array}$ & 19 & $1 \mathrm{~m}$ & Normal & $\begin{array}{l}\text { End to end anastomosis } \\
\text { not on bypass }\end{array}$ & $\begin{array}{l}\text { Seizures; EEG: low amplitude } \\
\text { activity discharges right>left }\end{array}$ & Normal & 12 \\
\hline $\begin{array}{l}\text { Arch anomalies (IAA, } \\
\text { VSD) }\end{array}$ & 21 & $6 \mathrm{~d}$ & $\begin{array}{l}\text { Respiratory arrest } \\
\text { and period of } \\
\text { hypotension at } \\
\text { home (partial } \\
\text { DiGeorge } \\
\text { syndrome) }\end{array}$ & $\begin{array}{l}\text { Reconstruction of aortic } \\
\text { arch on bypass }\end{array}$ & $\begin{array}{l}\text { Focal seizures right and left; } \\
\text { EEG: multifocal discharges } \\
\text { right>left poor activity in } \\
\text { between }\end{array}$ & $\begin{array}{l}\text { Squint, } \\
\text { microcephaly, } \\
\text { development delay }\end{array}$ & $\begin{array}{r}7 \\
8 \\
12\end{array}$ \\
\hline $\begin{array}{l}\text { Arch anomalies (IAA, } \\
\text { VSD) }\end{array}$ & 23 & $9 d$ & $\begin{array}{l}\text { Cardiac arrest, } \\
\text { seizures }\end{array}$ & Repair IAA, closure VSD & $\begin{array}{l}\text { Right focal seizures, dystonic } \\
\text { posturing to pain; EEG: low } \\
\text { amplitude both hemispheres, } \\
\text { bitemporal discharges. }\end{array}$ & $\begin{array}{l}\text { Right hemiplegia, global } \\
\text { developmental delay }\end{array}$ & 12 \\
\hline $\begin{array}{l}\text { Left sided valve lesion } \\
\text { (localised } \\
\text { supravalvular aortic } \\
\text { stenosis) }\end{array}$ & 22 & $168 \mathrm{~m}$ & Normal & Supravalvular aortoplasty & $\begin{array}{l}\text { Horner's syndrome, brachial } \\
\text { plexus injury }\end{array}$ & Normal & 12 \\
\hline $\begin{array}{l}\text { Complex (truncus } \\
\text { arteriosus } \\
\text { interrupted } \\
\text { pulmonary arteries) }\end{array}$ & 6 & $52 \mathrm{~m}$ & Normal & $\begin{array}{l}\text { Truncal valve replacement, } \\
\text { revision of homograft } \\
\text { (anastomosis left pul- } \\
\text { monary artery to right } \\
\text { pulmonary artery, con- } \\
\text { duit right ventricle to } \\
\text { pulmonary artery, patch } \\
\text { closure right ventricle) }\end{array}$ & $\begin{array}{l}\text { Seizures, coma, pyramidal signs; } \\
\text { EEG: generalised slow activity }\end{array}$ & Speech delay & 24 \\
\hline
\end{tabular}


$\mathrm{p}<0.001)$. One hundred and six patients in our study had circulatory arrest during cardiopulmonary bypass and although this period of time for the patients with adverse neurological events was longer (mean 44 minutes) compared with normal survivors (mean 25 minutes) and those who died (mean 27 minutes), this was not statistically significant.

Postoperatively, significantly more patients with adverse neurological events were ventilated for over 48 hours $(\mathrm{p}<0.05)$ and they had more periods of low MAP $(\mathrm{p}<0 \cdot 05)$.

Overall, of the 31 patients with adverse neurological events, $16(52 \%)$ had had a period of low MAP either intraoperatively or postoperatively, compared with $75(17 \%)$ of the subsequently normal patients $(\mathrm{p}<0.001)$. In addition, of the children with right ventricular outflow tract obstruction (the diagnosis in over one third of all patients with adverse neurological events), seven (64\%) had a period of low MAP and this compares with $25(22 \%)$ of the subsequently normal patients with this diagnosis $(p<0 \cdot 01)$. For those patients with adverse neurological events and arch anomaly as their diagnosis, four $(66 \%)$ had experienced a period of low MAP and this compares with only one (4\%) of patients in the arch anomaly group who were subsequently normal $(\mathrm{p}<0 \cdot 01)$.

Of the 31 patients with adverse neurological events, three died during the reported admission and five died at a later date. Four patients were lost to further follow up, three of these cases living abroad. The long term outcome of the remaining 19 patients together with their specific adverse neurological event, relevant investigations, and duration of follow up is shown in table 2 . In essence, patient numbers $8,12,13,15,16,17,19,22$, and 27 probably recovered from their perioperative insult whereas patient numbers $5,6,10,14,18,20$, $21,23,24$, and 29 , had evidence of long term sequelae.

\section{Discussion}

We have found that one in every 20 children undergoing cardiac surgery at this institution, during a one year time period, had an adverse neurological event in the immediate postoperative period. From the retrospective way in which our data were collected this must represent a minimum incidence, as it is likely that only the more severe or unusual neurological events would have been documented in the cardiac surgical discharge summaries, our initial source of reference. A recent survey seeking opinions from both paediatric neurologists and cardiac surgeons, reported a prevalence of neurological morbidity ranging from $2 \%$ to $25 \%$ (mean $8 \%$ ) at six major paediatric cardiac surgery programmes in North America. ${ }^{10}$ No published first hand data are available against which to compare our results, although in a similar retrospective study of neurological morbidity in survivors of paediatric cardiac surgery in the Northern region of England an incidence of $15 \%$ was found (A G Stuart et al, paper presented at the British Paediatric Meeting in York, April 1989).

Two mechanisms of neurological injury associated with cardiopulmonary bypass are postulated; microembolism (of air or particulate matter) and ischaemia, but their relative importance remains controversial. ${ }^{11}$ This was not a study of underlying aetiology, but we did have some evidence that a period of low perfusion pressure either intraoperatively or postoperatively was present in more patients who had an adverse neurological event that in those who were subsequently normal. Future prospective studies, investigating the influence of both intraoperative and postoperative perfusion pressure on subsequent neurological morbidity may help to determine the strength of this relationship.

Pre-existing neurological abnormalities in children before their cardiac surgery have been previously documented. In one study, preoperative neurological abnormalities were present clinically in 15 of $21(71 \%)$ patients before their corrective surgery. ${ }^{12}$ From this present study, 13 of the 31 children $(42 \%)$ with a subsequent adverse neurological event, had either a pre-existing neurological abnormality, for example, Down's syndrome, CHARGE association, or had experienced an event preoperatively that could have accounted for some of their abnormal postoperative neurology. Necropsy studies have confirmed central nervous system malformations in patients with congenital heart disease, specifically in those patients with TGA $(2-5 \%)$, Fallot's tetralogy (5-10\%), coarctation of the aorta (4-9\%), truncus arteriosus (4-10\%), and hypoplastic left heart syndrome $(2-10 \%) .1314$ These pre-existing abnormalities may in some way predispose towards further neurological injury during surgery.

The ICD9 system of classification cannot adequately account for the variety of congenital cardiac lesions or distinguish the differing effects on outcome of the precise nature of the lesion, for example between a simple TGA and a more complex TGA with additional intracardiac pathology or between a simple coarctation of the aorta and an interrupted aortic arch. It was for this reason that the regrouping was performed in an attempt to at least reflect the functional effect of the cardiac conditions encountered. Nevertheless, an interesting finding from this study was that the highest frequency of adverse neurological events was in the cardiac diagnostic group of arch anomaly. This group includes those patients who had simple coarctation, interrupted aortic arch, or hypoplastic arch.

These more severe forms of coarctation, often result in a preoperatively sick, acidotic and hypotensive infant, who may then undergo a technically complex repair (with, for example, in a hypoplastic arch clamping of the left carotid artery) and therefore it would not be surprising to isolate this group as potentially at high risk for neurological sequelae. As can be seen from the table of long term outcome, two of these patients had 'simple' coarctations 
and were repaired via a closed heart approach; all six had seizures as their adverse neurological event. A possible explanation for the high incidence of adverse neurological events among the arch anomalies is that embolism of air or particulate matter may result from manipulation of the arch. Also in simple coarctations repaired without the use of cardiopulmonary bypass, heparin is not administered which may also increase the risk from emboli. Our results also suggest that a period of low perfusion pressure may be a contributing factor in this group. One could also speculate that a preexisting midline brain abnormality, such as focal cortical dysplasia, could be associated with this midline arch defect and this could predispose to seizures. Certainly further research targeting this particular diagnostic group is warranted.

The most frequently noted adverse neurological event throughout the whole group was seizures, documented in 16 patients. This results in an overall frequency of $3 \cdot 1 \%$ of cases undergoing surgery. The reported incidence of postoperative seizures varies between $4 \%$ and $10 \%$, however, this quoted figure is for specific surgical procedures, for example, profound hypothermia and circulatory arrest rather than an overall frequency covering various forms of surgery. ${ }^{12} 15$ Only one child (number 29), with seizures as his postoperative adverse neurological event, continued with seizures on a long term basis (and this particular child had seizures associated with hypocalcaemia before his cardiac surgery). The rarity of long term seizures is consistent with the reported natural history of fits associated with cardiac surgery, ${ }^{15}$ but a follow up study, for example, of young adults, would be needed to exclude the possibility of epilepsy as an outcome.

In summary, of our 19 children with adverse neurological events in the immediate postoperative period for whom some long term follow up data are available, nine probably recovered from their perioperative insult, of whom only three had been normal preoperatively. Ten patients remained with long term neurological sequelae, all of these had substantial perioperative adverse neurological events. In four of these, it is difficult to determine the relative contribution of immediate preoperative from intraoperative/postoperative insults. The remaining six had been completely normal preoperatively and their subsequent sequelae must be directly related to the period surrounding their cardiac surgery.

This represents a significant proportion of children and families whose lives may well have been impaired, despite correction of their cardiac abnormality. It must also represent a significant cost in terms of long term provision of both medical and rehabilitation services. Further research to limit the development of this neurological damage must continue to be actively supported.

The authors thank Dr Stewart Boyd (neurophysiologist), Dr Kate Bull (paediatric cardiologist), and Dr Robert Surtees (statistical advice)

PF was supported by a grant from the British Heart Foundation and JMA by a grant from Junta Nacional de Investigação Cientifica e Tecnológica (JNICT)-Programa Ciênica, Lisbon.

1 Lansing AM, Giradat RE, Masri Z. Mortality in pediatric 944 operations. F Ky Med Assoc 1984; 82: 273-7.

2 Ferry PC. Neurologic sequelae of cardiac surgery in children. Am $\mathcal{F}$ Dis Child 1987; 141: 309-12.

3 Elliott MJ. Perfusion for pediatric open heart surgery. Semin Thorac Cardiovasc Surg 1990; 2: 332-40.

4 Kirklin JK, Westaby S, Blackstone EH, Kirklin JW, Chenoweth DE, Pacifico AD. Complement and the damaging effects of cardiopulmonary bypass. $f$ Thorac Cardiovasc Surg 1983; 86: 845-57.

5 Newburger JW, Jonas RA, Wernovsky G, et al. A comparison of the perioperative neurologic effects of hypothermic circulatory arrest versus low-flow cardiopulmonary bypass in infant heart surgery. $N$ Engl F Med 1993; 329: 1057-64.

6 Fallon P, Roberts I, Kirkham FJ, et al. Cerebral hemodynamics during cardiopulmonary bypass in children using near-infrared spectroscopy. Ann Thorac Surg 1993; 56: 1473-7.

7 Tasker RC, Matthew DJ, Helms P, Dinwiddie R. Monitoring in non-traumatic coma. Part 1: invasive intracranial measurement. Arch Dis Child 1988; 63: 888-94.

8 Kirkham FJ. ICP and CBF in non-traumatic coma in childhood. In: Minns RA, ed. Problems of ICP in childhood. (Clinics in developmental medicine No 113/114.) Mac Keith Press, 1991: 283-348.

9 De Leval MR, François K, Bull C, Brawn W, Spiegelhalter D. Analysis of a cluster of surgical failures. halter $\mathrm{D}$. Analysis of a cluster of surgical failures. Application to a series of neonatal arterial switch ope
tions. $\mathcal{F}$ Thorac Cardiovasc Surg 1994; 107: 914-24.

10 Ferry PC. Neurologic sequelae of open heart surgery in children. Am f Dis Child 1990; 144: 369-73.

11 Taylor KM. Brain damage during cardiac surgery. Current Opinion in Cardiology 1986; 1: 697-701.

2 Brunberg JA, Reilly EL, Doty DB. Central nervous system consequences in infants of cardiac surgery using deep hypothermia and circulatory arrest. Circulation 1974; 50 (suppl 2): 60-6.

13 Glauser TA, Rorke LB, Weinburg PM, Clancy RR. Congenital brain anomalies associated with the hypoplastic left heart syndrome. Pediatrics 1990; 85: 984-90.

14 Okada R, Johnson D, Lev M. Extracardial malformations associated with congenital heart disease. Archives of Pathology 1968; 85: 649-57.

15 Ehyai A, Fenichel GM, Bender HW. Incidence and prognosis of seizures in infants after cardiac surgery with prognosis of seizures in infants after cardiac surgery with 1984; 252: 3165-7. 